\title{
Teaching Reform of the Course of Automatic Control Theory Based on Engineering Cases
}

\author{
Jialin Wang and Xuanfang Yang* \\ College of Electronic Engineering, Naval Univ.of Engineering, Wuhan 430033, China \\ "Corresponding author.Email: 18162625263@163.com
}

\begin{abstract}
Based on enriching the teaching resources and improving the quality of classroom teaching, combined with the current curriculum standards, class hours, teaching materials and other specific requirements, the construction of the engineering case database of the course of automatic control principle is carried out, and the engineering case is applied to classroom teaching practice, the traditional classroom teaching mode is reformed, and the project-based and discussion based teaching is carried out based on the engineering case to improve the teaching effect. This paper puts forward the specific methods and approaches for the construction of the engineering case resource base, studies the selection, processing design and optimization scheme of the engineering case according to the needs of the specific teaching content, and the completed engineering case has been used in the teaching practice of the automatic control principle course, which has played a positive role in promoting the quality of personnel training.
\end{abstract}

Keywords: engineering cases, automatic control theory, Teaching reform

\section{INTRODUCTION}

The course of "the principle of automatic control" is an important basic course of university engineering.At present, the course of automatic control theory in our university has the characteristics of wide teaching range, involving many specialties, etc., and now it's a university excellent course.With the revision of personnel training program and curriculum standard, the teaching object, teaching content, teaching requirements (practical teaching requirements, information environment conditions, etc.) and the teaching staff of the course of automatic control theory have changed a lot, so the teaching reform of the course is imperative[1].

\section{THE MAIN PROBLEMS IN THE TEACHING OF AUTOMATIC CONTROL THEORY}

For a long time, how to teach the course of the principle of self-control has been a difficult problem for university teachers. The course of automatic control theory is characterized by rich teaching content, strong theoretical nature, close connection with basic courses such as mathematics, involving a wide range of knowledge, abstract concept content, many exercises, and great difficulty.Abstract teaching content makes students feel difficult to understand, and a large number of mathematical derivation process makes classroom teaching boring, students sound boring, and it is difficult to stimulate students' interest in learning[2].
Because our school-based curriculum team is mainly composed of young teachers, most of them have a single experience and relatively narrow professional knowledge, and the classroom teaching of automatic control theory is mainly based on mathematical derivation of formula theorem, emphasizing theory rather than practice, which cannot combine with engineering examples to teach the physical meaning of abstract concepts and affect the teaching effect.On the other hand, due to the lack of appropriate engineering cases and teaching resources[3], teachers cannot introduce engineering examples with professional characteristics according to the specific situation of the teaching class. The introduction of new courses is mostly based on circuit as an example. In fact, there are a large number of practical cases of control theory application in communication engineering, power engineering and other professional fields [4].

According to the analysis of the feedback from the supervision experts, the questionnaire survey was carried out for the students. Combined with the teachers\&apos; own teaching experience, the main problems in the teaching of the principle of self-control were as follows:

(A) The existing teaching focuses on abstract theoretical knowledge and mathematical deduction, which is not closely related to engineering practice, and the teaching of physical concepts, engineering cases and practical applications is not enough, which leads to the unclear purpose of students\&apos; learning and the lack of enthusiasm and initiative in learning[5].

(B) The classroom teaching mode is single, with the traditional indoctrination teaching as the main mode, the teaching interaction is not enough, the classroom atmosphere is dull, and the teaching effect is not good. 
(C) The teaching process only pays attention to the teaching of knowledge and the explanation of exercises, but does not pay attention to the cultivation of engineering quality and innovation ability, so the teaching quality is not high.

\section{MAIN IDEAS AND METHODS OF COURSE CONSTRUCTION OF AUTOMATIC CONTROL THEORY BASED ON ENGINEERING CASES}

The construction of engineering case base is a basic project to enrich teaching resources and improve teaching quality.By selecting typical control engineering cases to establish a rich teaching case base and introducing appropriate engineering practical cases for analysis in the teaching process, students can understand the abstract concepts and theoretical knowledge in the course of automatic control theory, and have a more intuitive feeling for the whole process of mathematical modeling, system analysis and system design of control system. Through case teaching, students can learn .The ability of senior students to analyze and solve problems with their knowledge.Rich case base is helpful for the reform and implementation of teaching mode, and enables young teachers to have the conditions and confidence to carry out discussion and project teaching.Therefore, the construction of case base is of great significance to improve teaching effect and ensure teaching quality.The main ideas and methods of course construction of automatic control theory based on engineering cases are as follows:

\subsection{Set up case base construction team}

Set up the construction group of case teaching resource base of automatic control theory engineering, and the task is decomposed to each teacher.The project leader is responsible for top-level planning and design, case selection, content requirements and construction standards. The backbone teachers are responsible for the collection, sorting, construction and development of the original case materials. The lecturer is responsible for drawing, simulation programming and PPT optimization of each specific case.

Guided by the course construction of automatic control theory, guided by the advanced teaching concept, supported by modern education technology, aimed at improving the quality of classroom teaching, with the front-line backbone teachers of the course group as the main body, based on the characteristics of the course and the actual needs, according to the content and key points of the construction of the case resource base of automatic control theory engineering, the division of labor and cooperation, the collective efforts and joint construction are carried out[6].

\subsection{Combination of multiple ways to build project case database}

Through collecting and sorting, downloading on the Internet, research and development and other ways, the case material database of automatic control theory engineering is constructed.First of all, we should fully excavate and sort out the existing teaching resources and materials, and obtain free public teaching resources of various media and online open courses, such as the teaching materials of domestic related professional boutique courses and foreign open courses.Secondly, we should selectively supplement the CD-ROM teaching resources attached to all kinds of teaching materials[7].Finally, combined with related research projects, such as ship dynamic positioning control system and ship autopilot control system, the project case is designed and produced by independent research and development.Through a variety of ways to combine, establish a wealth of engineering cases of the original material library.

\subsection{Select materials and build case base with chapter content and knowledge points as the main line}

There are many types of repeated engineering cases in the original material database of engineering cases collected by different ways, which need to be screened and merged; some original engineering cases lack of detailed background introduction, specific system parameters, or simulation analysis process, which cannot be directly used in teaching, and need to be screened and processed.According to the curriculum standard arrangement, with chapter contents and knowledge points as the main line, select engineering cases with obvious professional characteristics from the original material database, process and make, supplement the necessary background introduction and simulation analysis process, and form a complete teaching case.

In the process of case selection and processing, on the one hand, it is necessary to strengthen the engineering application background of control theory, and pay attention to the practical application of main knowledge points in the case; on the other hand, it is necessary to avoid involving too much and too deep power electronics professional knowledge, not falling into the discussion of complex control system design, and always adhere to the foundation of practical innovation[8].

\subsection{Based on the classroom teaching, continuously optimize, perfect and enrich the case base}

The construction of case resource base is a process of dynamic update and continuous improvement. It is 
necessary to give full play to the enthusiasm of all teachers in the course group in building the case base, and to give full play to the enthusiasm of teachers in applying the case to classroom teaching and constantly optimizing the improvement. According to the actual needs of case teaching, the image, animation and video materials should be supplemented appropriately.In the construction and use of case base, attention should be paid to the co construction and sharing of resources to form a resource construction community. The construction of teaching case base needs hard work. Only by giving full play to the joint construction of all teachers in the course group, can every teacher share rich teaching materials, so as to achieve the fundamental purpose of improving the teaching quality as a whole.Through the co construction and sharing of teaching cases, the improvement of classroom teaching practice and regular exchange mechanism, all teachers of the course group are motivated to participate in the dynamic updating and construction of teaching cases, so that the case base is in a good state of continuous use and development.

\subsection{Applying engineering cases to reform classroom teaching mode}

The purpose of construction of engineering case resource base is application. The role of engineering cases in classroom teaching is not only reflected in the introduction of problems (introducing new knowledge and content through actual engineering cases), the explanation and explanation of abstract concepts (intuitively explaining the physical meaning of abstract concepts through specific engineering examples), but also in the application of control principles and methods (enabling students to understand the role of abstract control theories by solving engineering example problems) It is also reflected in the strong supporting role for the reform of classroom teaching mode.Based on the comprehensive engineering project cases, young teachers have the conditions and confidence to carry out project teaching and discussion teaching. The teaching cases are designed with chapter content and knowledge points as the main line. Each chapter has at least 1-2 comprehensive engineering project problems, which need to be analyzed and solved by using the knowledge learned in this chapter.After learning the content of this chapter, one project-based or seminar based teaching can be carried out. The teacher will provide the students with engineering cases and problems in advance, make brief introduction and explanation, arrange task requirements, group the students, make use of spare time preparation, and divide the work to be responsible for drawing, pushing calculation, programming simulation analysis and preparation of reports. Finally, each group will conduct summary in class as required Report and simulation demonstration, teachers guide students to comment on each other, carry out problem discussion and in-depth exploration, and students\&apos; performance shall be included in their usual performance.Through the reform of the traditional classroom teaching mode, project- based teaching and discussion teaching are carried out based on the project cases and specific project tasks. Through mutual cooperation, students can use the control theory knowledge they have learned to solve specific practical engineering problems, not only deepen the understanding of the control theory knowledge, but also demonstrate the students\&apos; obvious sense of achievement through reporting, greatly improving The students\&apos; initiative in learning has been improved, and their comprehensive quality and abilities in many aspects have been cultivated.

\subsection{Design of teaching method based on mind map}

Mind map is an effective graphic thinking tool to express divergent thinking. It can enhance the memory effect by using the form of pictures and texts. It takes the form of both text and text. It shows the relationship of all levels of topics by the hierarchical graph of mutual subordination and correlation, and establishes memory links between subject keywords, images and colors. Different from the traditional way of Linear recording, mind mapping emphasizes the logical relationship and hierarchical relationship between key words, and reflects the internal logic of various basic concepts in the course in a rich graphical way, so it is very conducive to the understanding of concepts and active thinking. More importantly, the knowledge organization form of mind map conforms to the natural thinking mode of human brain, has the learning interaction mode and multi-sensory learning characteristics in line with brain neurophysiology, so it is particularly conducive to creative thinking and divergent discussion in the process of discussion teaching.

The implementation process of discussion teaching includes:

First, create mind maps. There are many knowledge points in this course, but the logical relationship between each knowledge point is clear. The following problems should be paid attention to in drawing mind map:

At the beginning of drawing, the teacher will introduce the concept elements to be drawn, and the students will discuss and complete the connection and hierarchical relationship between the elements;

When using the directed line segment to identify the relationship between elements, it is necessary to explain its theoretical basis. For example, when deriving "necessary and sufficient conditions for the stability of linear systems" from the definition of stability, a brief reason should be provided.

In the process of drawing, we need to pay attention to the hierarchical relationship between conceptual elements. For example, the Routh criterion is a simple method to determine the closed-loop pole position according to the coefficients of the characteristic polynomial of the system, so it should be placed in the next level of "sufficient and necessary conditions for stability". In the teaching process, many students think that the Routh criterion is also a 
condition for the stability of the control system. These unclear concepts can be clearly reflected after the establishment of mind map.

\section{CONCLUSION}

In view of the problems of abstract teaching content and insufficient connection of theory with practice in the course of automatic control theory, the construction of engineering case base for the course of automatic control theory is carried out based on enriching teaching resources and improving the quality of classroom teaching, combined with the current curriculum standards, class hours, teaching materials and other specific requirements, and the engineering cases are applied to the classroom teaching practice to reform the traditional classroom teaching mode and carry out project-based and discussion based teaching based on engineering cases, so as to improve the teaching effect.This paper puts forward the specific methods and approaches for the construction of the project case resource base; according to the needs of the specific teaching content, studies the selection, processing design and optimization scheme of the project case, and the completed project case has been used in the teaching practice of the automatic control theory course, which has played a positive role in improving the quality of personnel training.

\section{REFERENCES}

[1] Wu Ling. The exploration of the reform of automatic control principle assisted instruction based on QQ platform Electronics World, vol.09, PP.71-72,2020.

[2] Shen Lu. Research on teaching reform of automatic control principle under the background of new engineering. Technology Wind,vol.14,PP.43+51,2020.

[3] Fan Shicai, Zhang Jiyang.Teaching reform of "automatic control principle".Education Teaching Forum,vol.17,PP.166-167,2020.

[4] Zhang Jie. Teaching reform and discussion of the course "principle of automatic control" under the teaching mode of Applied Undergraduate Colleges and universities. Science \& Technology Information, vol.18, no. 9,PP.7677,2020 .

[5] Wang Yan, Ling Dan, Zheng Anping, Jiang Liying. The reform and thinking of the teaching of automatic control principle under the background of engineering education certification. Contemporary Education Research and Teaching Practice,vol.5,PP.81-82,2020.

[6] Zhao Jing, Wei bin, Chen Mingshu, Wan Shaosong, Shang Anli. The reform of test form and experiment of "automatic control principle" teaching method [J]. Education Teaching Forum,vol.8,PP.230-231,2020.
[7] Wang fenqin. Reform and practice of experiment teaching of modern automatic control principle. China Plant Engineering,vol.1,PP.207-208,2020.

[8] Zhan Manting. Research on teaching reform of "automatic control principle" [J]. Journal of Wuxi South Ocean College,vol.17,no.Z1,PP46-48,2019. 